\title{
Discriminating non-seismic long-period pulses and noise to improve earthquake source inversion
}

Takahide Sakai ${ }^{1}$, Hiroyuki Kumagai ${ }^{1 *}$, Nelson Pulido ${ }^{2}$, Jun Bonita ${ }^{3}$ and Masaru Nakano ${ }^{4}$

\begin{abstract}
Broadband seismometers produce artifacts resembling long-period pulses (non-seismic pulses) that degrade centroid moment tensor (CMT) estimations based on waveform inversion of broadband seismic records in long-period bands (50-200 s). We propose a method to discriminate non-seismic pulses and long-period noise from seismic signals, which can be applied to automatic CMT inversion analysis. In this method, we calculate source amplitudes as peakto-peak displacement amplitudes in individual long-period seismic records after each event has been corrected for medium attenuation and geometric spreading and then estimate the ratios of individual source amplitudes to the minimum source amplitude. Because source amplitude ratios for non-seismic pulses tend to be greater than those of the seismic signals, we use seismic records in CMT estimations only if their source amplitude ratios are lower than a threshold value $(R)$. We tested this method using broadband seismic data from the Philippines and found that reprocessed inversion solutions using this method showed a clear improvement when using $R=11$, although focal mechanism estimations were not entirely stable. To investigate the general applicability of this method, we analyzed broadband seismic data from F-net in Japan. Our analysis indicated that source amplitude ratios in F-net data ranged up to about 20, indicating that the threshold value may be dependent on station density. Given that F-net is one of the highest density networks in the world, we may assume that a threshold value between 10 and 20 is appropriate for application of our method for most regional broadband networks. Our synthetic tests indicated that source amplitude ratios can be as high as $10^{3}$, although observed ratios are only within the range $10-20$. This suggests that we happened to observe only events having focal mechanisms with source amplitude ratios of 10-20. Alternatively, these high source amplitude ratios can be explained by distortion of radiation patterns in the long-period band, which reduces maximum source amplitude ratios and affects CMT estimates.
\end{abstract}

Keywords: Centroid moment tensor, Waveform inversion, Source amplitude, SWIFT system, Broadband seismometer

\section{Findings}

\section{Background}

Broadband seismic networks have been deployed in various regions of the world. Centroid moment tensor (CMT) solutions for earthquakes are routinely estimated by using broadband waveform data from global networks (Dziewonski et al. 1981; Sipkin 1994; Ekström et al. 2012). Near-real-time CMT inversions are performed

\footnotetext{
*Correspondence: kumagai@eps.nagoya-u.ac.jp

${ }^{1}$ Graduate School of Environmental Studies, Nagoya University, Furo-cho,

Chikusa-ku, Nagoya 464-8601, Japan

Full list of author information is available at the end of the article
}

using regional networks in Japan (e.g., Kawakatsu 1995; Fukuyama et al. 1998; Ito et al. 2006; Tsuruoka et al. 2009), California, USA (e.g., Dreger et al. 1998), New Zealand (Ristau 2008, 2013), Italy (Scognamiglio et al. 2009), Indonesia (Nakano et al. 2008, 2010a), the Philippines (Punongbayan et al. 2015; Bonita et al. 2015), and elsewhere. For large earthquakes beneath the ocean, rapid and correct CMT estimation is essential for prediction of tsunamis and evaluation of possible seismic and tsunami hazards.

It is recognized that broadband seismometers produce long-period pulse-like artifacts (Zahradník and Plešinger 2005, 2010; Delorey et al. 2008). These non-seismic

\section{Springer Open}


pulses resemble the instrumental response to a step input in acceleration (Zahradník and Plešinger 2005) and occasionally appear during ground shaking. Such long-period pulses degrade CMT estimations based on waveform inversion of broadband seismic records in a long-period band, which may cause serious problems in tsunami prediction and early hazard assessment. Because the exact cause of the artifacts is unclear and there is no established way to correct for them, a method is needed to discriminate non-seismic pulses from seismic signals and avoid using waveform data including non-seismic pulses in automatic source inversion analysis.

Recently, a broadband seismic network was established in the Philippines (Melosantos et al. 2015). This network consists of 12 broadband stations with real-time telemetry to the central office of the Philippine Institute of Volcanology and Seismology (PHIVOLCS) (Fig. 1a). Using real-time data from the network, a source inversion analysis system called SWIFT (Nakano et al. 2008, 2010a, source parameter determination based on waveform inversion of Fourier transformed seismograms) automatically determines a CMT solution for an earthquake of moment magnitude greater than 4.5 within 15 min of the start of the earthquake. The estimated source information is used by PHIVOLCS to issue tsunami warnings. Non-seismic long-period pulses and other long-period noise have frequently appeared in broadband seismic records from the network in the Philippines (Fig. 2) and have degraded automatic CMT solutions. This is a critical problem in using an automatic solution for tsunami warning.

In this paper, we propose a simple method to improve automatic CMT solutions by discriminating non-seismic pulses and long-period noise from usable waveform data, and we show that our method may be generally applicable to CMT analysis in other regional broadband seismic networks.

\section{Methods \\ SWIFT system}

The SWIFT system developed by Nakano et al. (2008) estimates both the moment function and CMT based on waveform inversion of long-period seismic signals in the frequency domain, which enables efficient and rapid computations. SWIFT assumes a point source and a pure double-couple source mechanism in order to stabilize the solution when using data from a small number of stations. A spatial grid search of strike, dip, and rake angles identifies the best-fitting fault parameters and the source centroid that minimizes the normalized residual between the observed and synthetic displacement seismograms in the frequency domain. Because band-passed waveforms are used in the inversion, the resultant moment function is a band-passed form. The seismic moment is estimated from the moment function deconvolved from its bandpassed form (Nakano et al. 2008). SWIFT has been used to study source mechanisms of earthquakes in various regions: Indonesia (Nakano et al. 2008, 2010a, b), the Philippines (Punongbayan et al. 2015; Bonita et al. 2015), Turkey (Görgün 2013; Görgün and Görgün 2015; Nakano et al. 2015), and Japan (Ando et al. 2012; Kumagai et al. 2012).

In the Philippines, the SWIFT system is triggered by receipt of an email at PHIVOLCS providing earthquake information determined by the SeisComP3 system (https://www.seiscomp3.org/) if an estimated earthquake magnitude $(M)$ is greater than 4.5 . Waveform data at individual stations within $1500 \mathrm{~km}$ of the epicenter are retrieved between $10 \mathrm{~min}$ before and $9 \mathrm{~min}$ after the earthquake origin time. The unprocessed waveform data are first checked for amplitude saturations and data gaps, and a band-pass filter between 50 and $100 \mathrm{~s}$ is then applied to the data that are free of saturations and gaps. The noise and signal amplitudes are estimated from peak-to-peak amplitudes during periods $200 \mathrm{~s}$ before and $482 \mathrm{~s}$ after the origin time, respectively, in each bandpassed waveform. The band-passed waveforms with signal-to-noise amplitude ratios greater than 4 are selected. If the number of selected waveforms is greater than 4 and the selected waveforms are from more than 2 stations, the SWIFT inversion is performed. The waveform data are decimated to a sampling frequency of $0.5 \mathrm{~Hz}$, and a total length of $512 \mathrm{~s}$ (30 s before and $482 \mathrm{~s}$ after the origin time) is used. The hypocenter given by SeisComP3 is used as an initial source location for the spatial grid search in which we use the adaptive grid spacing of Nakano et al. (2008). At each source node, a grid search of fault parameters (strike, dip, and rake angles) is conducted, and waveform inversion in the frequency domain is performed to estimate the moment function (band-passed form) for each combination of angles. We adopt the fault parameter and source location showing the minimum residual, in which the deconvolved form of the moment function is estimated to determine the seismic moment and moment magnitude $\left(M_{\mathrm{w}}\right)$. If the estimated $M_{\mathrm{w}}$ is greater than 7.0, the above processes are repeated for the waveform data band-passed between 50 and $200 \mathrm{~s}$. Each automatic solution is manually checked, and the waveform traces including non-seismic pulses and long-period noise are discarded. A manual solution is then obtained by inversion using the selected waveform traces. Bonita et al. (2015) showed that the manual SWIFT CMT solutions for earthquakes in and around the Philippines were consistent with the corresponding CMT solutions estimated by the Global CMT Project (http://www.globalcmt.org/). 

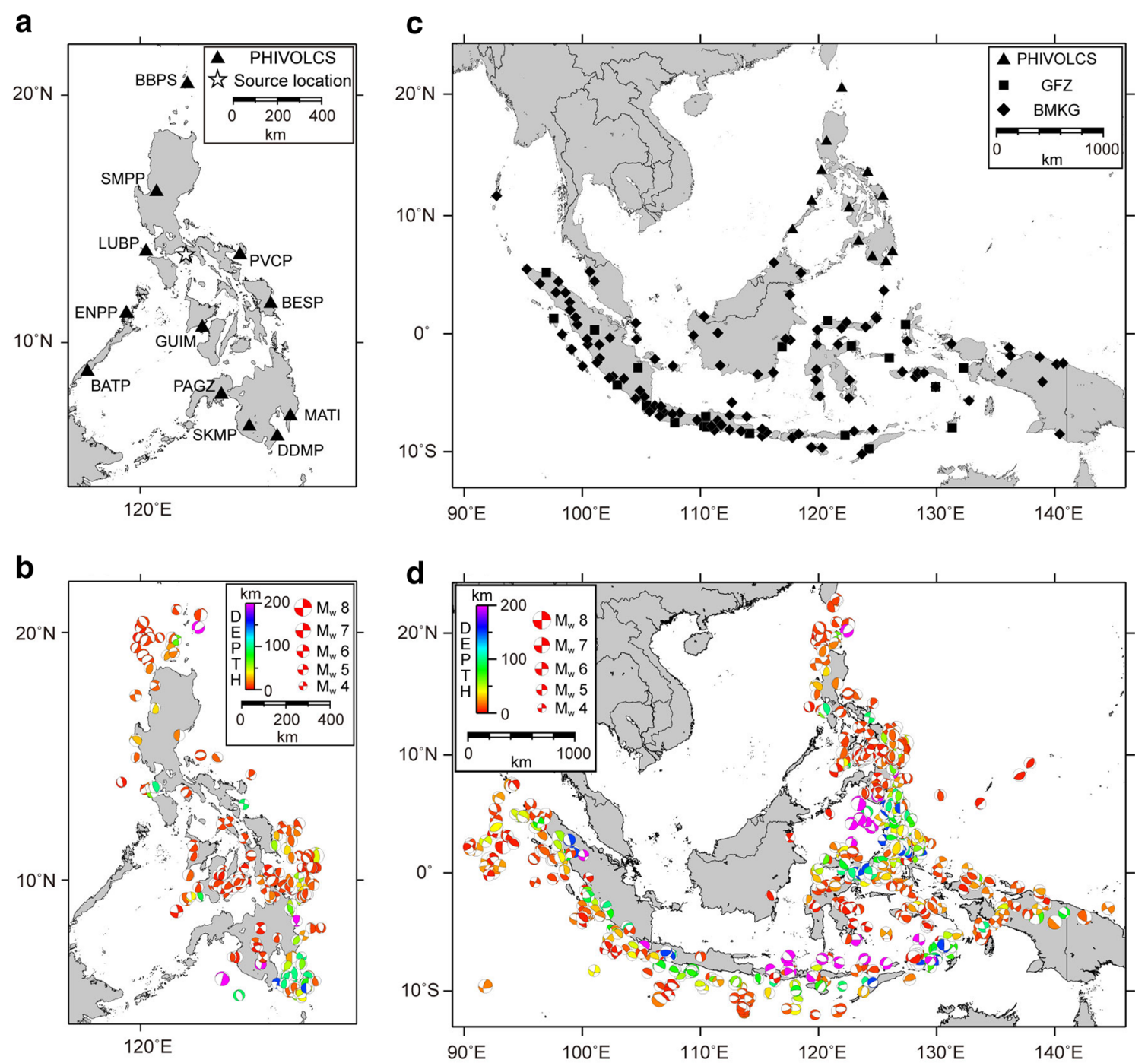

Fig. 1 Locations of broadband seismic stations and focal mechanisms, and moment magnitudes of earthquakes in (a, b) the Philippines and (c, d) Indonesia. The Indonesia network is maintained by Badan Meteorologi Klimatologi dan Geofisika, Indonesia (BMKG) and GeoForschungsZentrum Potsdam, Germany (GFZ). Focal mechanisms are based on CMT solutions determined by NIED. Star in (a) is the source location used in synthetic tests

\section{Source amplitude}

Because the non-seismic pulses appear during ground shaking and their pulses are similar in shape to bandpassed seismic signals, their detection by automatic processes is difficult. We noticed during our manual checks of automatic solutions that the non-seismic pulses in long-period bands tend to have higher amplitudes than the seismic signals. Such anomalously high amplitudes of non-seismic pulses especially affect inversion solutions. To evaluate the amplitudes of seismic signals in a longperiod band, we use the source amplitude $A_{i}$ (Battaglia and Aki 2003) assuming a surface wave given as

$$
A_{i}=U_{i} \sqrt{r_{i}} \exp \left(B r_{i}\right)
$$

where $B=\pi f /(Q \beta), U_{i}$ is the peak-to-peak displacement amplitude of the $i$ th waveform trace band-passed between 50 and $100 \mathrm{~s}$ or 50 and $200 \mathrm{~s}, r_{i}$ is the epicentral distance of the $i$ th trace, $f$ is the frequency, $\beta$ is the surface wave velocity, and $Q$ is the quality factor for medium attenuation. We use $f=0.015$ or $0.0125 \mathrm{~Hz}$ (the average of the pass-band frequencies). We also use $\beta=3500 \mathrm{~m} / \mathrm{s}$ and $Q=300$, their typical values at shallow depth. We note that $A_{i}$ is less dependent on $\beta$ and $Q$ values. Because our objective is to develop a method that can simply and 

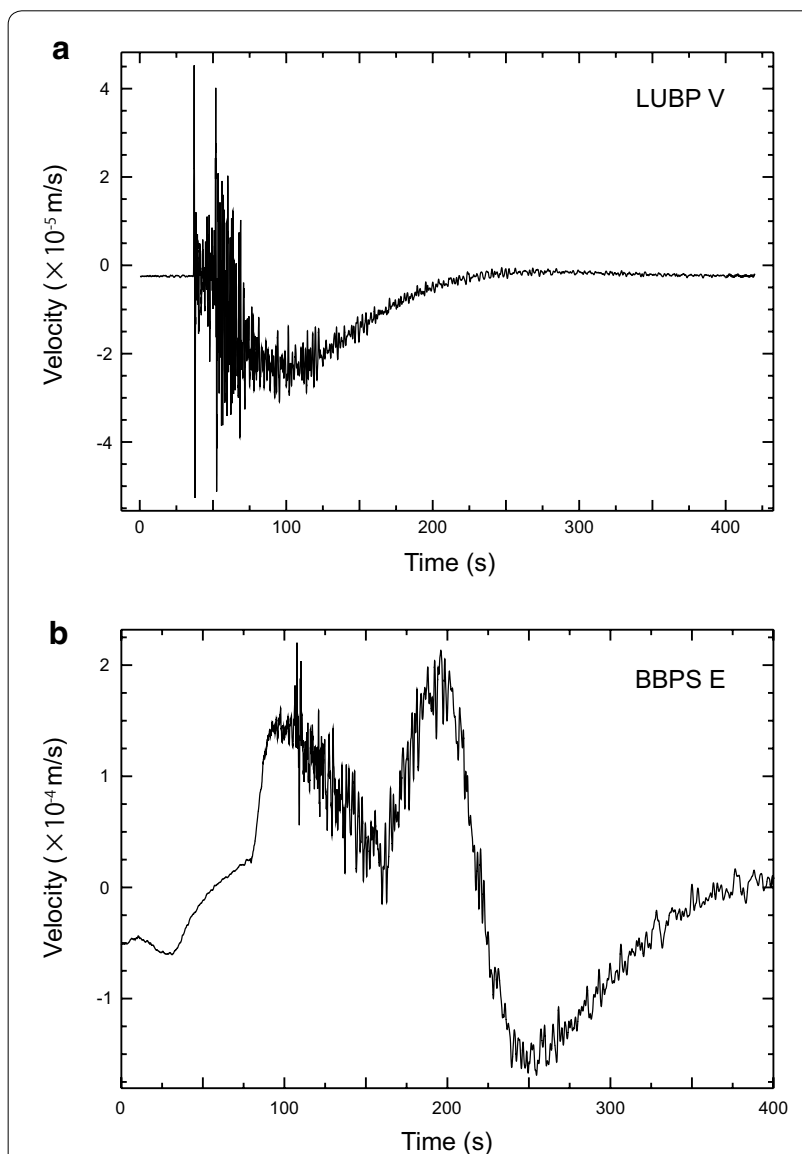

Fig. 2 Typical waveforms of $\mathbf{a}$ non-seismic pulse and $\mathbf{b}$ long-period noise, both low-pass filtered at $1 \mathrm{~Hz}$

rapidly discriminate non-seismic pulses and long-period noise from seismic signals, for simplicity, we do not consider the surface wave types.

\section{Results}

\section{Automatic CMT solutions}

We examined automatic CMT solutions determined by the SWIFT system for 191 events in the Philippines from June 2013 to November 2014. Figure 3 shows an example of an automatic solution that has been affected by nonseismic pulses. In this example, three-component waveform traces at station LUBP were contaminated by large non-seismic pulses. The CMT solution was affected and the source was determined at a shallow depth south of and close to this station (Fig. 3a, b). If we excluded the three waveform traces containing the non-seismic pulses, the resultant manual inversion solution showed a different mechanism and location (Fig. 3a) with reasonable waveform fits (Fig. 3c). We found the manual solution to be consistent with that estimated by the Global CMT Project.

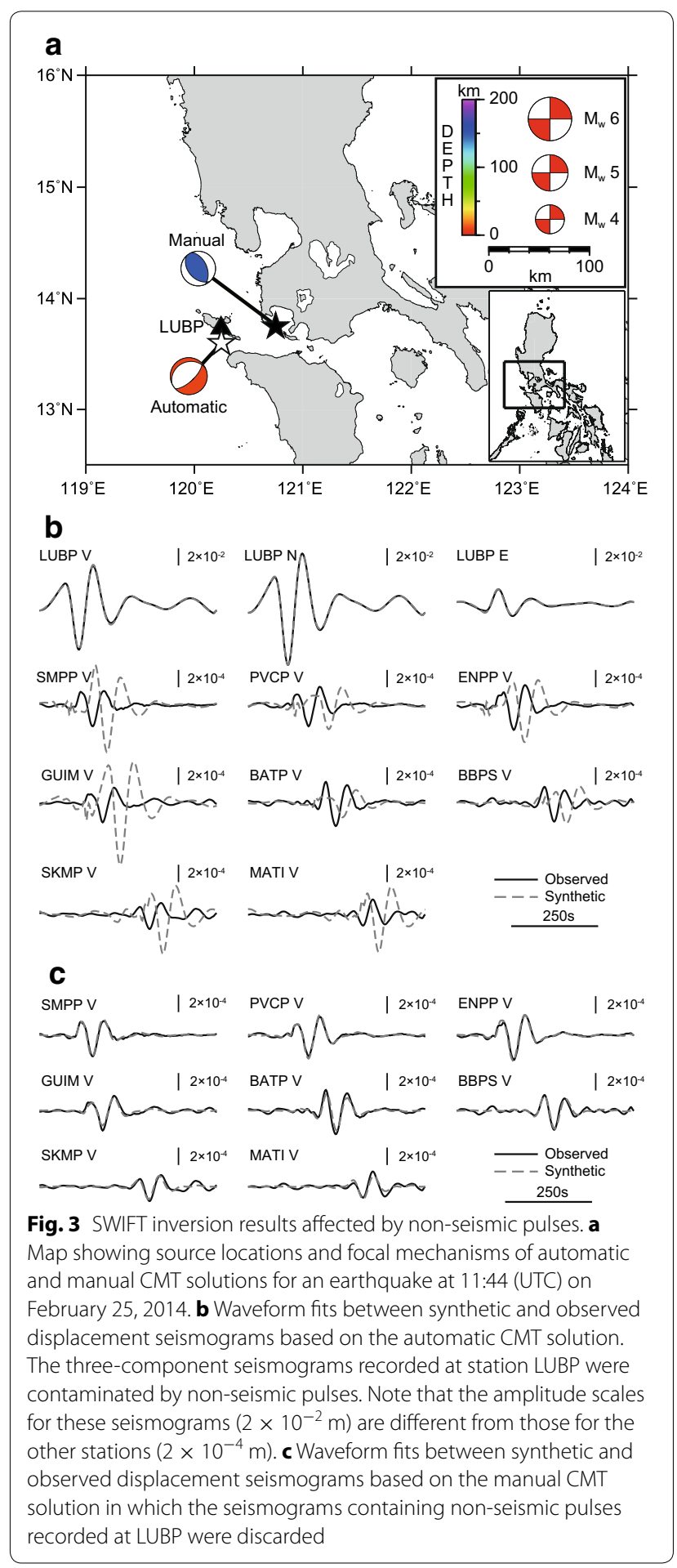

We compared the 191 automatic solutions with their corresponding manual solutions and found that 24 of the automatic solutions provided degraded CMT solutions in which source locations for the automatic and manual solutions differed by more than $50 \mathrm{~km}$. These 24 
solutions were clearly degraded by non-seismic pulses and long-period noise.

\section{Source amplitudes for automatic and manual CMT solutions}

For each of the 191 automatic CMT solutions, we calculated the source amplitudes of individual waveform traces selected by the automatic process and the initial source location determined by SeisComP3. We plotted the source amplitudes for all of the automatic solutions as a function of $M_{\mathrm{w}}$ (Fig. 4a). We also plotted in Fig. 4a the source amplitudes for manual solutions of earthquakes that occurred in Indonesia and the Philippines regions in 2012-2014 (Fig. 1d), which were estimated by the National Research Institute for Earth Science and Disaster Prevention (NIED; http://www.isn.bosai.go.jp/ en) using seismic data from the broadband seismic networks in the Philippines and Indonesia (Fig. 1c). The source amplitudes for all CMT solutions (both automatic and manual) showed a vertical scatter (Fig. 4a), but only those for the manual solutions (black open circles) clearly increased with increasing $M_{\mathrm{w}}$; this trend may be a function of radiation patterns. The scatter of source amplitudes for individual degraded automatic CMT solutions (red open circles) was large and vertical.

We estimated the ratios of the individual source amplitudes to the minimum source amplitude for each event (Fig. 4b). Most of the amplitude ratios for the manual CMT solutions were less than 10 and showed no dependence on $M_{\mathrm{w}}$, whereas those of the degraded automatic solutions had ratios greater than 10 (Fig. $4 \mathrm{~b}$ ). We thus considered whether a threshold value of source amplitude ratios might be useful to discriminate non-seismic pulses and long-period noise from seismic signals.

\section{Application of the source amplitude ratio method}

We ran SWIFT inversions for the waveform traces in the 24 degraded automatic CMT solutions, excluding waveform traces with source amplitude ratios greater than a threshold $R$ (for $R$ values from 9 to 12), and compared the resultant inversion solutions with the corresponding manual solutions. Our analysis indicated that the squared sum of the difference in the source locations for the reprocessed automatic and manual CMT solutions was lowest for $R=11$. The reprocessed automatic solutions were clearly improved by application of this method as shown in Figs. 5 and 6. Source locations for the reprocessed automatic and manual CMT solutions were less than $100 \mathrm{~km}$ apart for all but three events, and for 17 events, they were less than $50 \mathrm{~km}$ apart. The corresponding differences in $M_{\mathrm{w}}$ were less than 0.5 for all but three events. To evaluate the differences in the CMT mechanisms, we estimated the Kagan angles (Kagan 1991, 2007) for the reprocessed automatic and manual mechanisms and for the original automatic and manual CMT mechanisms. The Kagan angle is defined as the minimum angle of rotation in three-dimensional space from one CMT to the other, which is a measure of the difference between the orientations between two mechanisms. As shown in Fig. 7, the reprocessed automatic CMT solutions were improvements over the original automatic solutions; however, more than half of them showed Kagan angles greater than $30^{\circ}$, indicating that the mechanism estimation was still not entirely stable. Although the matches of the manual and reprocessed automatic CMT solutions were not perfect, the reprocessed solutions showed a clear improvement.
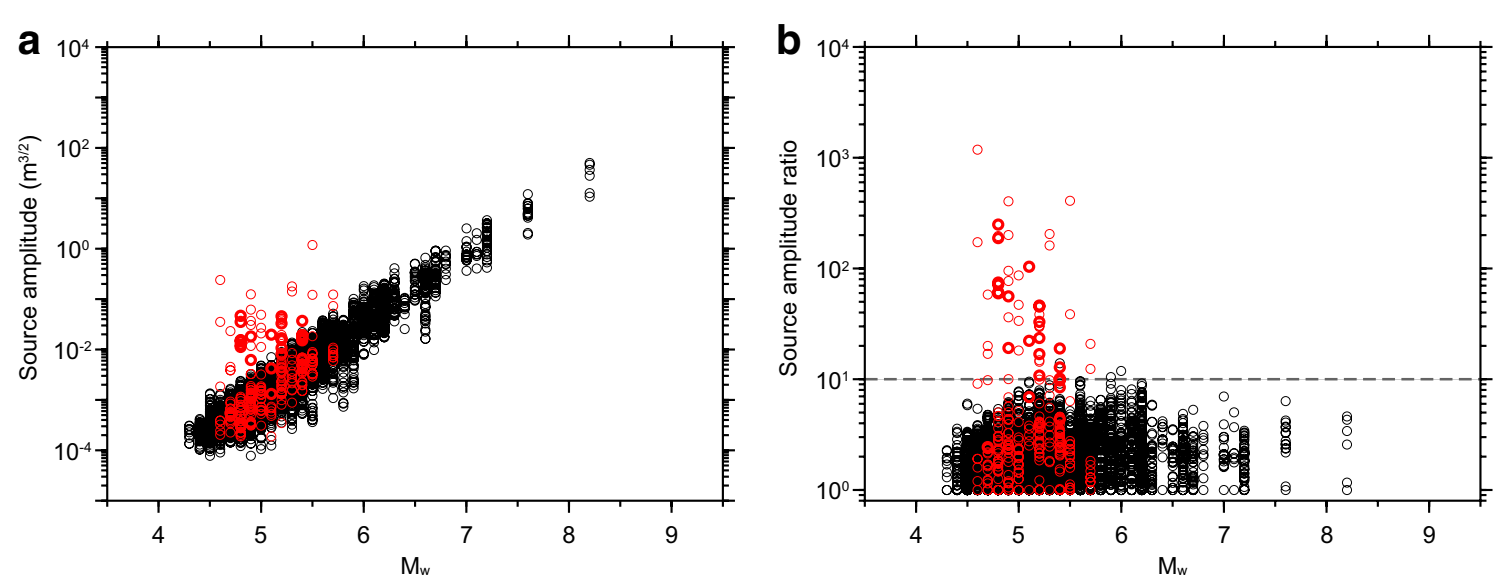

Fig. 4 a Source amplitude versus moment magnitude for manual CMT solutions (black circles) of earthquake events in the Philippines and Indonesia and for automatic CMT solutions (red circles) of events in the Philippines. b Source amplitude ratios calculated from source amplitudes shown in (a) versus moment magnitude. Bold red circles are source amplitudes and source amplitude ratios of non-seismic pulses 

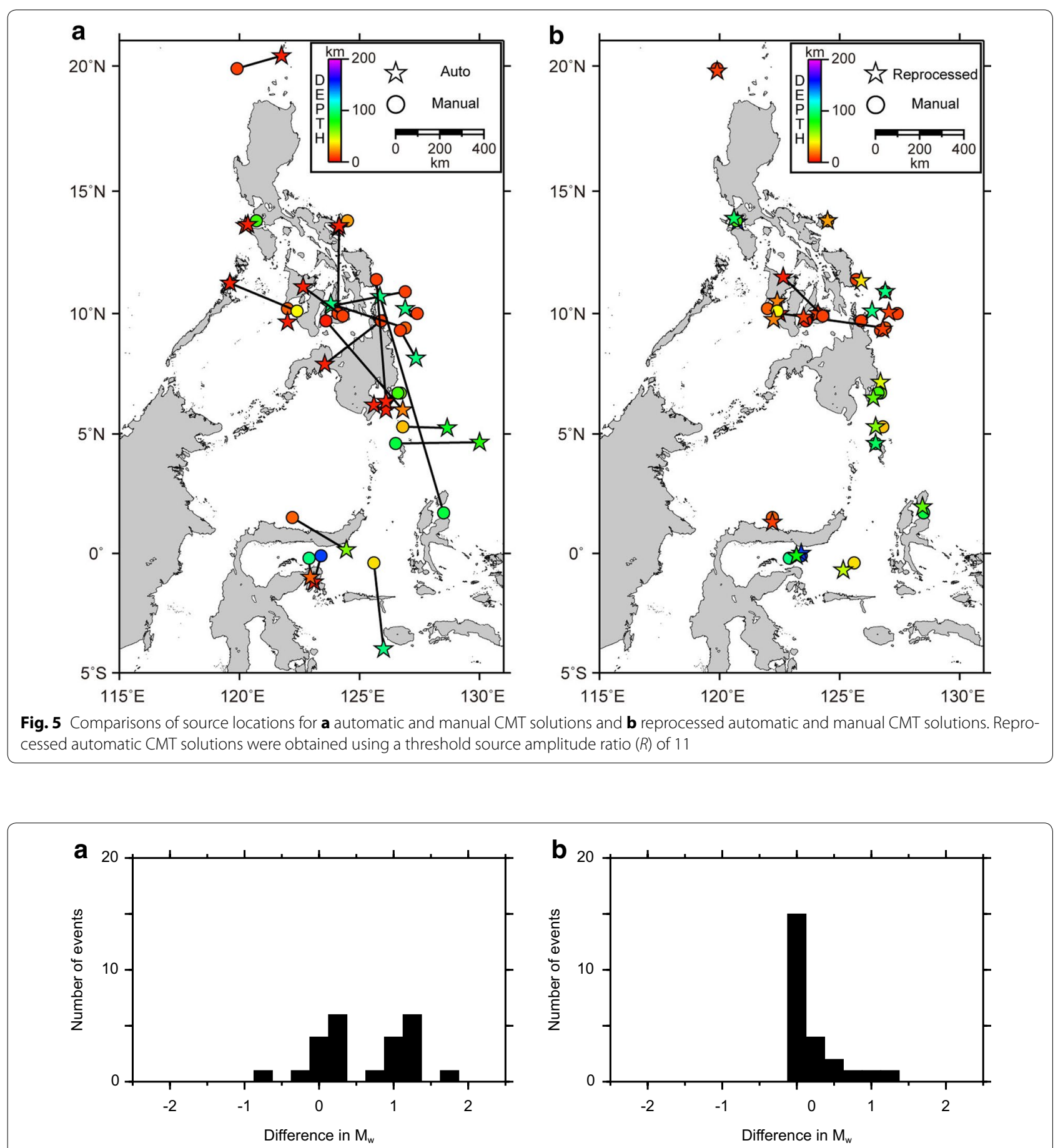

Fig. 6 Differences in moment magnitudes obtained for a automatic and manual CMT solutions and $\mathbf{b}$ reprocessed automatic and manual CMT solutions

\section{Source amplitudes of F-net data}

Our method relies on the value of the threshold of source amplitude ratios used, which may depend on the source mechanism and station distribution. Source mechanism controls radiation patterns and station distribution controls azimuthal coverage to the source, which together affect the detectability of seismic signals. To investigate this effect, we analyzed broadband seismic data recorded by F-net in Japan (Fig. 8a), one of the highest density broadband seismic networks in the world 


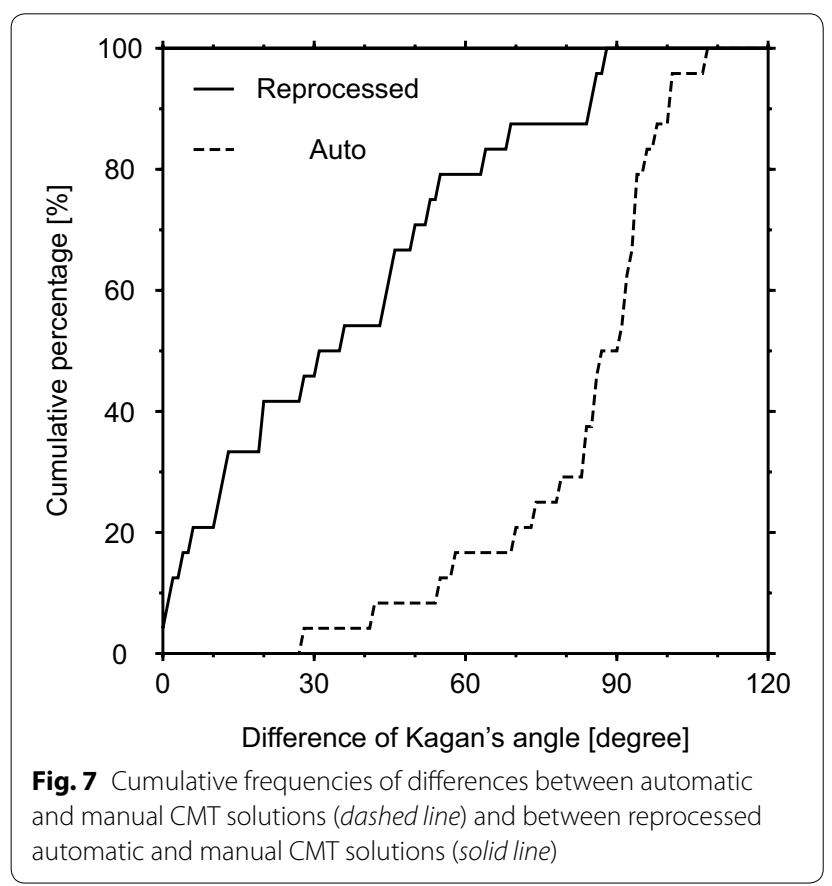

(Okada et al. 2004; Matsumoto et al. 2009). Each F-net station consists of a broadband seismometer and a velocity-type strong-motion seismometer placed in a tunnel of $30-50 \mathrm{~m}$ length, and they provide low-noise broadband seismic records with a wider range of signal amplitudes than the records from broadband seismic networks in the Philippines and Indonesia.

We examined Japanese earthquakes of $M_{\mathrm{w}} 4-9$ in the F-net catalog from 2003 to 2014 (Fig. 8b). We selected these events to include a variety of source mechanisms. For each event, we selected waveform data from F-net stations within $1500 \mathrm{~km}$ of epicenters and covering the period from 5 min before to $10 \mathrm{~min}$ after earthquake origin time. For events of $M_{\mathrm{w}}<7$, we used waveform data recorded by broadband seismometers; for $M_{\mathrm{w}} \geq 7$, we used waveform data recorded by both broadband seismometers and velocity-type strong-motion seismometers. We selected waveform data for which the signal-to-noise amplitude ratio of the band-passed waveforms was greater than 4 , the same data selection method as for the automatic process of the SWIFT system. We excluded waveform data that contained amplitude saturations, data gaps, non-seismic pulses, and long-period noise. We then estimated source amplitudes and source amplitude ratios and considered their relationships to moment magnitude (black circles in Fig. 9). Source amplitudes increased with increasing $M_{\mathrm{w}}$ (Fig. 9a) with a trend similar to that of the data from the Philippines and Indonesia (Fig. 4a). Most of the source amplitude ratios were less than about 20 (Fig. 9b), which is a higher value than in the data from the Philippines and Indonesia (Fig. 4b). This difference may reflect the difference in the station distributions and indicates that source
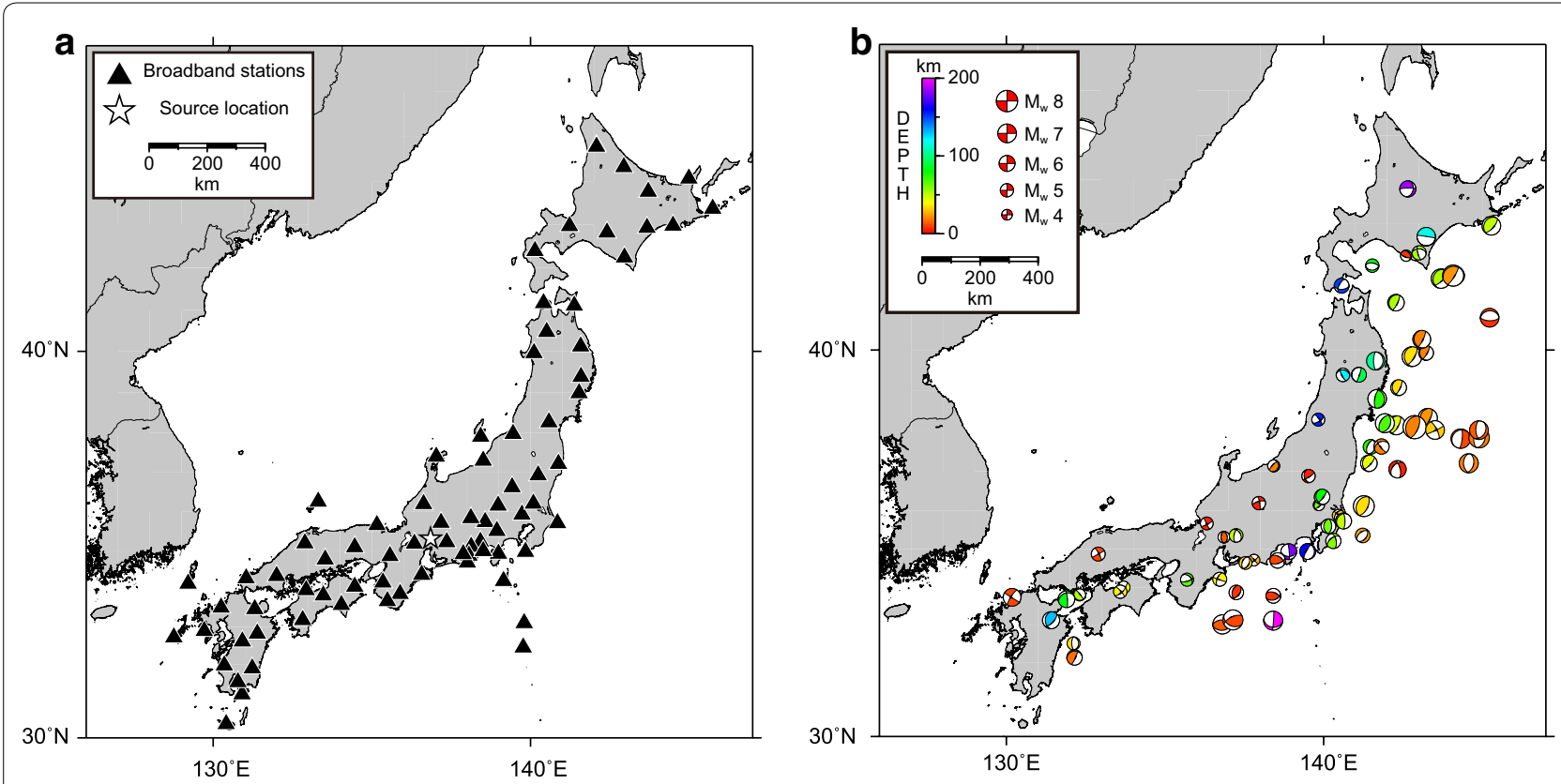

Fig. 8 Locations of $\mathbf{a}$ F-net stations and $\mathbf{b}$ earthquakes used in our analysis of source amplitudes. Focal mechanisms are CMT solutions in the F-net catalog (http://www.fnet.bosai.go.jp/event/joho.php?LANG=en). Star in $(\mathbf{a})$ is the source location used in our synthetic tests 

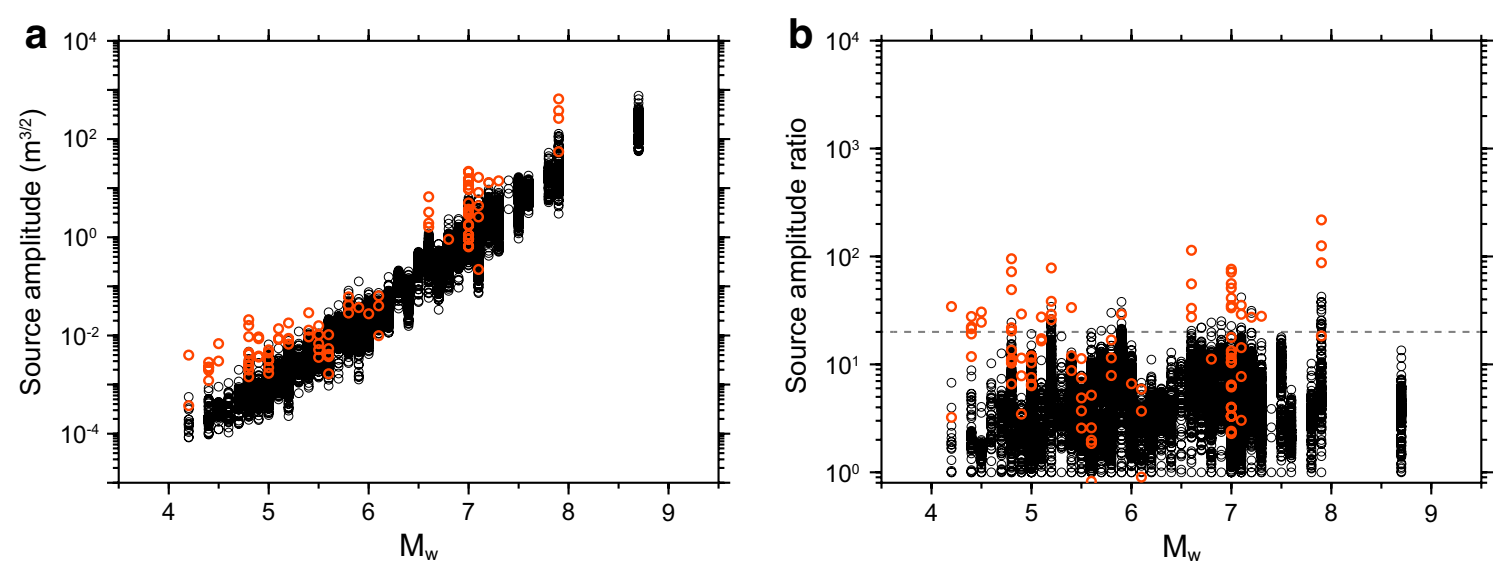

Fig. 9 a Source amplitude and $\mathbf{b}$ source amplitude ratio versus moment magnitude for F-net data (black circles) shown in Fig. 8b. Orange circles are source amplitudes and source amplitude ratios of non-seismic pulses and long-period noise

amplitude ratios may be dependent on the station density of networks.

\section{Source amplitudes of synthetic and observed seismograms}

To examine the dependence of the source amplitude ratios on source mechanism and station distribution, we performed numerical tests using synthetic seismograms calculated by the discrete wavenumber method (e.g., Bouchon 1979). To synthesize seismograms, we used the standard earth model ak135 (Kennet et al. 1995) and the station distributions of F-net and the Philippines network. We used the CMT mechanisms and locations of events in the Philippines (Fig. 1b) and Japan (Fig. 8b) estimated by NIED, and synthesized three-component seismograms at individual stations for both networks. We applied band-pass filters of 50-100 s for events of $M_{\mathrm{w}}<7.0$ and of 50-200 s for those of $M_{\mathrm{w}} \geq 7.0$ and excluded seismograms if their maximum amplitudes were less than 4 times the amplitude of typical noise for each network, thus following the waveform selection procedure for the observed data. We used noise amplitudes of $6.0 \times 10^{-8}$ and $7.0 \times 10^{-8} \mathrm{~m}$ for F-net and the Philippines network, respectively. These noise amplitudes correspond to peak values estimated from the observed data used in this study. Source amplitudes and source amplitude ratios of the synthetic data plotted as a function of $M_{\mathrm{w}}$ (Fig. 10) show a similar relationship to those of the observed data (Figs. 4, 9).

To estimate the theoretical range of source amplitude ratios, we assumed earthquake locations near the center of each network (Figs. 1a, 8a) and systematically changed strike, dip, and rake angles at $10^{\circ}$ intervals to synthesize three-component seismograms at individual stations of the F-net and the Philippines network for $M_{\mathrm{w}}$ between
4 and 8 by using the same process as described above. Source amplitudes for the resultant synthetic seismograms had lower limits at around $10^{-4} \mathrm{~m}^{3 / 2}$ (Fig. 11a, b), which reflect our waveform selections based on noise levels. These lower limits roughly coincided with those of the observed source amplitudes for events of $M_{\mathrm{w}}<5.0$ in the combined Indonesia-Philippines network and F-net (Figs. 4a, 9a, respectively) and led to increasing maximum source amplitude ratios with increasing magnitudes up to around $M_{\mathrm{w}}=6$ for both F-net and the Philippines network (Fig. 11c, d). Similar increases are evident in the observed maximum source amplitude ratios (Figs. 4b, $9 b)$, but only up to around $M_{\mathrm{w}}=5.0$.

We grouped all of the focal mechanisms into the four classes of Frohlich (1992): thrust, normal, strike-slip, and odd mechanisms. Using the synthetic data for $M_{\mathrm{w}}=6.5$, which were not affected by our noise-level selections, we estimated the normalized frequency distributions of the synthetic source amplitude ratios for each mechanism group (Fig. 12) and showed that the maximum synthetic source amplitude ratio is dependent on focal mechanism, that the strike-slip and odd mechanisms provided higher source amplitude ratios than thrust and normal mechanisms and that the synthetic source amplitude ratios ranged up to roughly $10^{3}$. Such higher amplitude ratios were mainly caused by small amplitudes near the nodal planes.

We also grouped the observed events in the Philippines (Fig. 1b) and Japan (Fig. 8b) into the four classes of mechanism on the basis of the NIED estimated CMT mechanisms and calculated the normalized frequency distributions of the source amplitude ratios for each class (Fig. 13). Although the odd mechanism events showed the maximum source amplitude ratios for each network, a result similar to that of our synthetic tests (Fig. 12), 


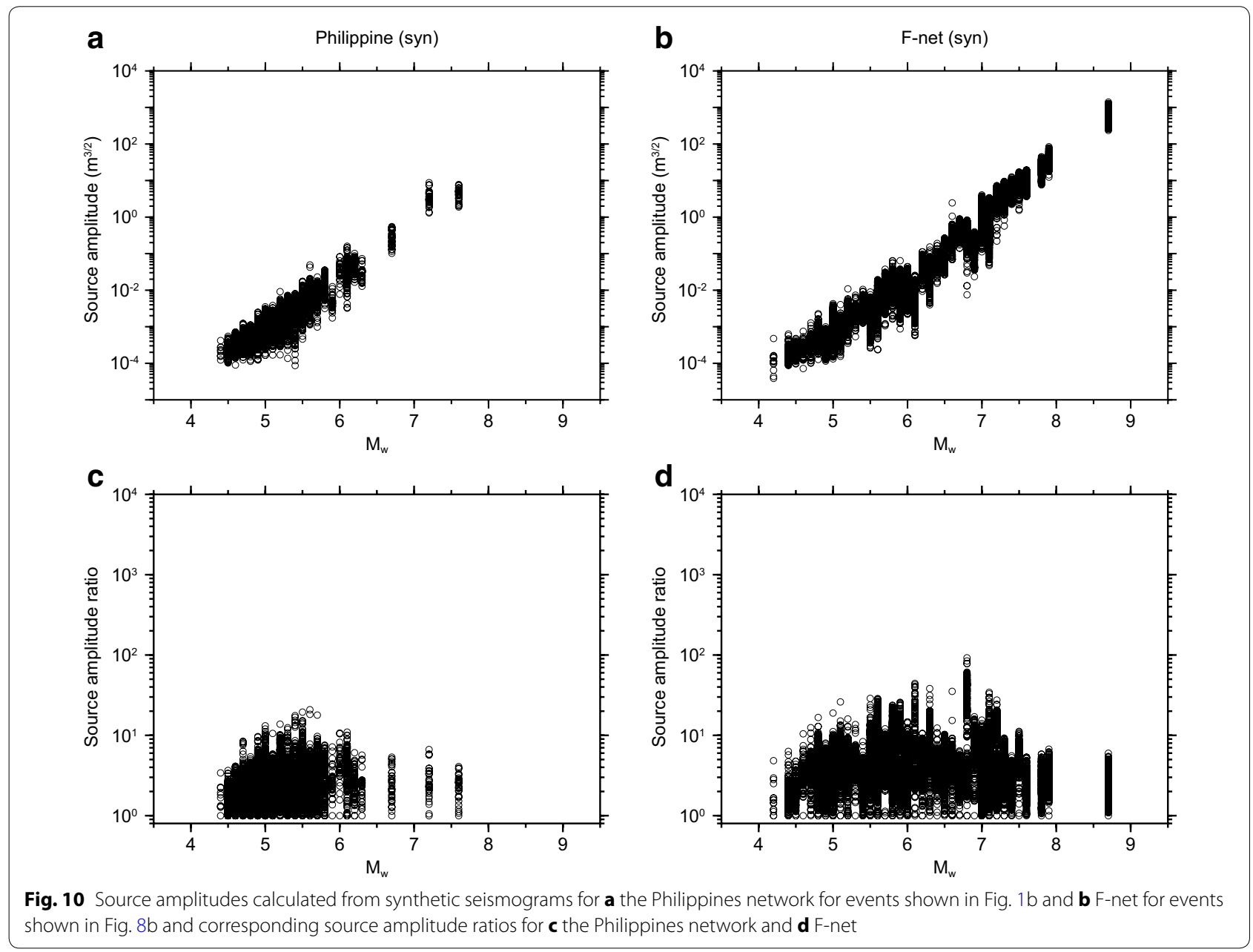

the maximum ratios for observed and synthetic data are clearly different.

\section{Discussion}

Kawakatsu (1995) proposed a method of automatic CMT inversion that discarded waveforms with maximum-tominimum ratios of root-mean-square amplitudes that were greater than 300 in long-period (45-100 s) seismograms at individual stations. We tested this method on the data providing the degraded CMT solutions from the Philippines network. We found that only three seismograms including the non-seismic pulses and long-period noise exceeded the threshold ratio of 300, whereas 45 seismograms including them were discriminated by our method using the source amplitude ratios with $R=11$. As the threshold ratio was lowered, more non-seismic pulses and noise were discriminated, but seismic signals were also included. This approach using amplitude ratios is useful to discard seismograms containing transient spikes. However, our study demonstrated that to discriminate non-seismic pulses and long-period noise, source amplitude ratios provide a more effective means of discrimination than amplitude ratios.

Our analysis of data from F-net and from broadband seismic networks in the Philippines and Indonesia indicated that source amplitudes increase with increasing $M_{\mathrm{w}}$ and that the range of source amplitude ratios is dependent on station density and focal mechanism. Maximum source amplitude ratios were around 10 for the Philippines and Indonesia networks and around 20 for F-net. This suggests that observations with a higher station density network provide better azimuthal coverage of source radiation patterns and result in larger $R$ values. Given that F-net is among the highest density broadband seismic networks in the world, we can assume that the appropriate threshold of source amplitude ratio for application of our method lies between 10 and 20 and that it may be applicable for most of the regional broadband networks deployed to date.

Comparison of automatic and manual CMT solutions reprocessed after applying our method to data from the Philippines network showed a clear improvement. 


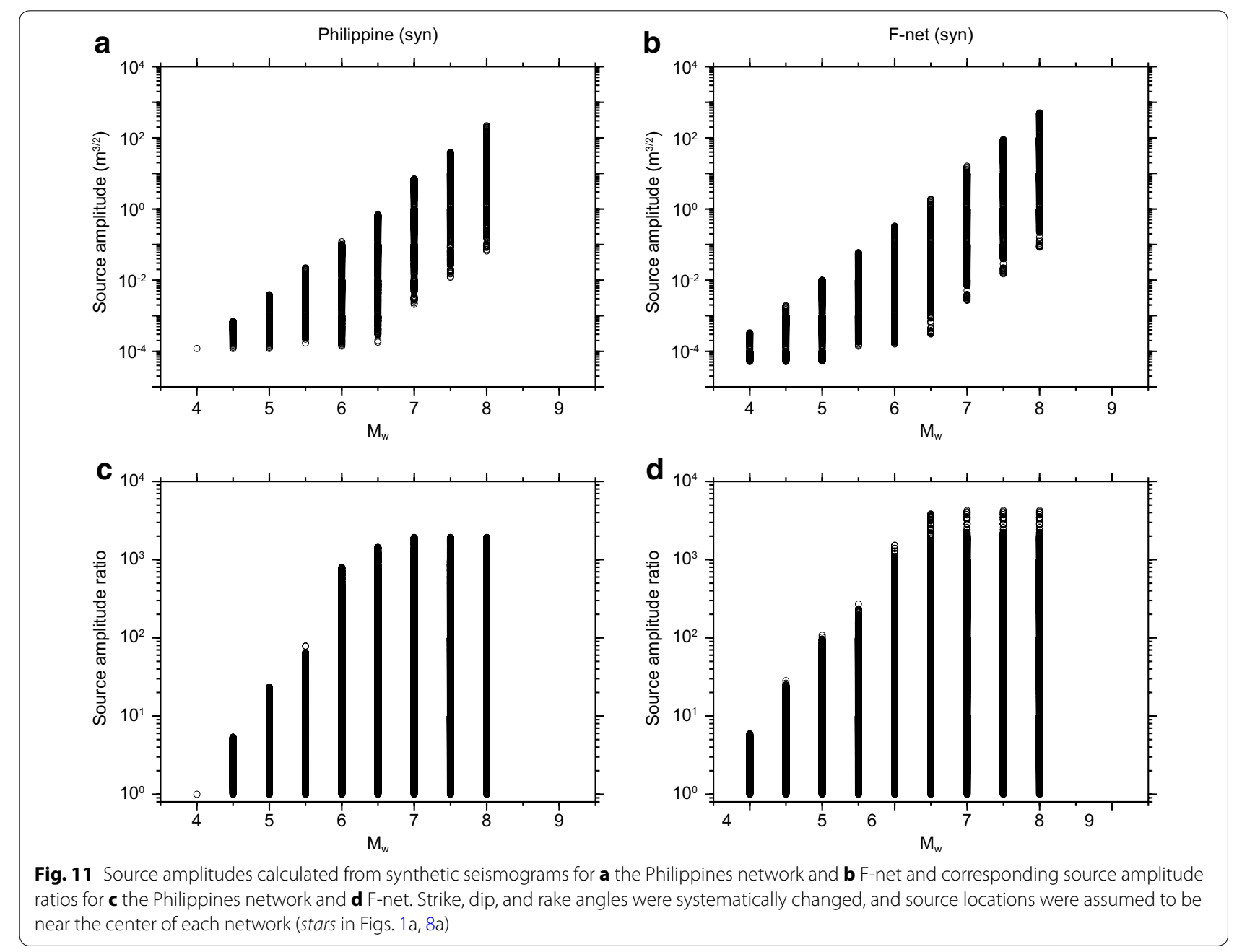

However, the results were not a perfect match and that the mechanism estimations were not entirely stable. We attributed the difference to the inability of our method to identify non-seismic pulses and long-period noise for source amplitude ratios less than the threshold, in which pulse and noise amplitudes were comparable to or smaller than seismic signal amplitudes. Our analysis of F-net data also indicated the existence of non-seismic pulses and long-period noise with large and small source amplitude ratios (orange circles in Fig. 9). To discriminate such small pulses and noise from seismic signals is a fundamentally difficult problem and remains unresolved. Future research is required to discriminate them and to further improve the accuracy of automatic solutions.

Our synthetic tests showed that the source amplitude ratios of synthetic seismograms based on CMT mechanisms calculated by NIED for individual events recorded by the Philippines network and F-net were similar to the source amplitude ratios of observed data. However, when we systematically changed strike, dip, and rake angles, the resultant maximum source amplitude ratios for the synthetic data were about $10^{3}$, whereas the ratios in observed data are limited to the range 10-20. There are two plausible interpretations of this apparent inconsistency. One is that we happened to observe only events with focal mechanisms that produced source amplitude ratios within the range 10-20. Our synthetic tests showed that normalized frequencies decrease with increasing source amplitude ratio (Fig. 12), which indicates that very few events with mechanisms that produce larger source amplitude ratios were observed. The alternative interpretation is that distortion of radiation patterns in the long-period band reduces maximum source amplitude ratios and affects CMT estimates. Such distortion is known in high-frequency bands of around several hertz and has been explained by the path effect caused by scattering of seismic waves (e.g., Liu and Helmberger 1985; Takemura et al. 2009, 2015; Kumagai et al. 2010, 2011; Kobayashi et al. 2015). Because such scattering effects may not be dominant in the 


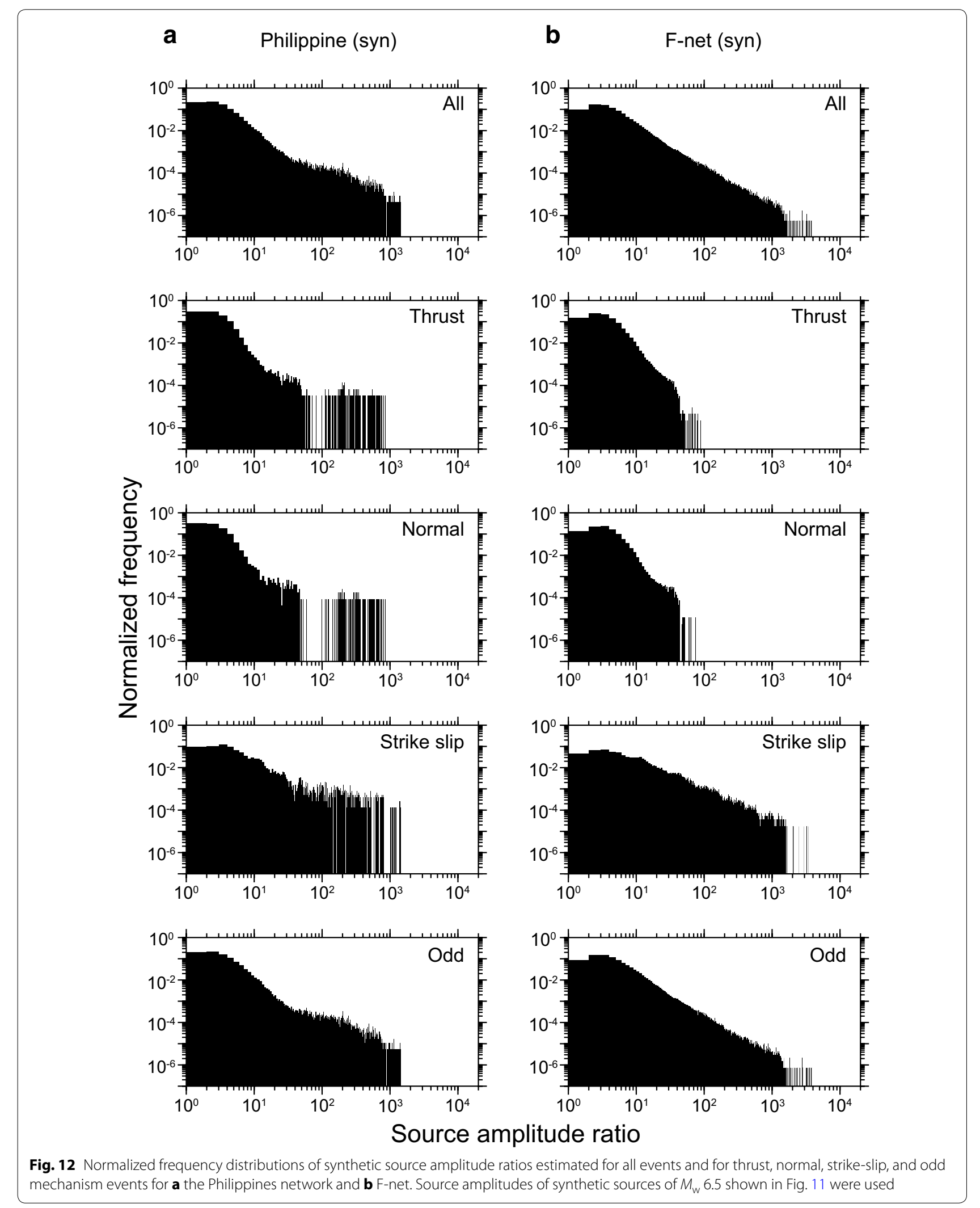




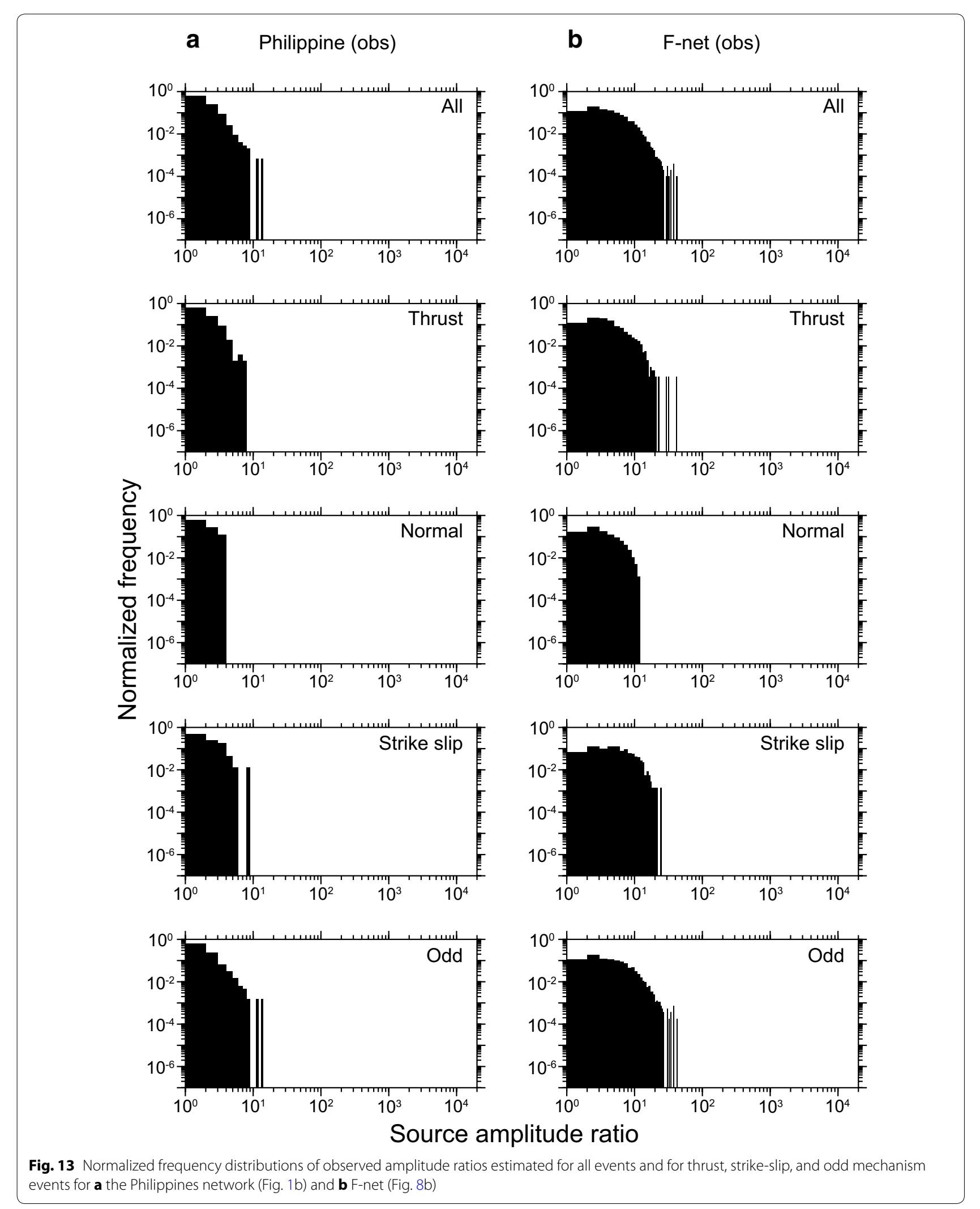


long-period band, wavefield distortion due to source finiteness and complexity and/or large-scale structures are possible causes. To validate these interpretations, we need further analysis of seismic waveform data and waveform simulations to be run for finite source rupture models in three-dimensional structures.

\section{Conclusions}

We analyzed automatic CMT solutions determined by the SWIFT system in the Philippines and found that they were affected by occasional long-period pulse-like artifacts and noise. To discriminate the non-seismic pulses and long-period noise from seismic signals and thus improve automatic inversion solutions, we investigated a method that uses source amplitude ratios estimated from individual waveforms. We set a threshold source amplitude ratio $(R)$ above which waveforms were excluded from CMT solutions on the basis that they included nonseismic pulses and long-period noise. We found that the degraded CMT solutions were clearly improved by applying our method with $R=11$, although the mechanism estimations were not entirely stable due to the existence of non-seismic pulses and long-period noise with source amplitude ratios less than the threshold.

Source amplitude ratios determined from waveform data from F-net in Japan, where station density is among the highest in the world, ranged up to about 20, which suggests that values of $R$ between 10 and 20 are appropriate for application of our method for most regional broadband seismic networks.

Although source amplitude ratios of synthetic seismograms based on CMT solutions for individual events in the Philippines network and F-net were similar to source amplitude ratios determined from observed data, systematically changing strike, dip, and rake angles in CMT estimations produced maximum source amplitude ratios of up to about $10^{3}$. This apparent inconsistency can be explained either by inclusion of only events with focal mechanisms that produce source amplitude ratios of $10-20$, or by distortion of radiation patterns in the long-period band that reduces maximum source amplitude ratios and affects CMT estimates. Future studies are needed to further improve the accuracy of automatic solutions and to investigate the physical meaning of the range of source amplitude ratios in observed data.

\footnotetext{
Authors' contributions

TS analyzed the seismic data and wrote a first draft of this paper. HK developed the basic concept of the present work and revised the first draft. NP and JB provided inversion results for data from the Philippines network and NP for data from the Indonesia network. MN developed the SWIFT inversion programs. All authors read and approved the final manuscript.
}

\section{Author details}

${ }^{1}$ Graduate School of Environmental Studies, Nagoya University, Furo-cho, Chikusa-ku, Nagoya 464-8601, Japan. ${ }^{2}$ National Research Institute for Earth
Science and Disaster Prevention, 3-1 Tennodai, Tsukuba, Ibaraki 305-0006, Japan. ${ }^{3}$ Philippine Institute of Volcanology and Seismology, Department of Science and Technology, C.P. Garcia Avenue, U.P. Campus, Diliman, Quezon City, Philippines. ${ }^{4}$ Japan Agency for Marine-Earth Science Technology, Kanazawa-ku, Yokohama, Kanagawa 236-0001, Japan.

\section{Acknowledgements}

We used data from F-net, which is managed by the National Research Institute for Earth Science and Disaster Prevention (NIED), Japan. We thank Jouji Senda for performing SWIFT inversion analyses. Comments from an anonymous reviewer and John Ristau helped to improve the manuscript. This work was supported by JST-JICA SATREPS.

\section{Competing interests}

The authors declare that they have no competing interests.

Received: 26 January 2016 Accepted: 9 March 2016

Published online: 01 April 2016

\section{References}

Ando M, Yu Y, Kumagai H, Yamanaka Y, Lin C-H (2012) Very low frequency earthquakes along the Ryukyu subduction zone. Geophys Res Lett 39:L04303. doi:10.1029/2011GL050559

Battaglia J, Aki K (2003) Location of seismic events and eruptive fissures on the Piton de la Fournaise volcano using seismic amplitudes. J Geophys Res 108:2364. doi:10.1029/2002JB002193

Bonita JD, Kumagai H, Nakano M (2015) Regional moment tensor analysis in the Philippines: CMT solutions in 2012-2013. J Disaster Res 10:18-24

Bouchon M (1979) Discrete wave number representation of elastic wave fields in three-space dimensions. J Geophys Res 84:3609-3614

Delorey AA, Vidale J, Steim J, Bodin P (2008) Broadband sensor nonlinearity during moderate shaking. Bull Seism Soc Am 98:1595-1601. doi:10.1785/0120070225

Dreger D, Uhrhammer R, Pasyanos M, Franck J, Romanowicz B (1998) Regional and far-regional earthquake locations and source parameters using sparse broadband networks: a test on the Ridgecrest sequence. Bull Seismol Soc Am 88:1353-1362

Dziewonski AM, Chou T-A, Woodhouse JH (1981) Determination of earthquake source parameters from waveform data for studies of global and regional seismicity. J Geophys Res 86:2825-2852. doi:10.1029/JB086iB04p02825

Ekström G, Nettles M, Dziewonski AM (2012) The global CMT project 2004-2010: centroid-moment tensors for 13,017 earthquakes. Phys Earth Planet Inter 200-201:1-9. doi:10.1016/j.pepi.2012.04.002

Frohlich C (1992) Triangle diagrams: ternary graphs to display similarity and diversity of earthquake focal mechanisms. Phys Earth Planet Inter 75:193-198

Fukuyama E, Ishida M, Dreger DS, Kawai H (1998) Automated seismic moment tensor determination by using on-line broadband seismic waveforms. Zisin 51:149-156 (in Japanese with English abstract)

Görgün E (2013) The 2011 October $23 M_{w} 7.2$ Van-Ercis, Turkey, earthquake and its aftershocks. Geophys J Int 195:1052-1967. doi:10.1093/gji/ggt264

Görgün E, Görgün B (2015) Seismicity of the 24 May $2014 M_{w} 7.0$ Aegean Sea earthquake sequence along the North Aegean Trough. J Asian Earth Sci 111:459-469. doi:10.1016/j.jseaes.2015.06.018

Ito Y, Sekiguchi S, Okada T, Honda R, Obara K, Hori S (2006) Performance of regional distance centroid moment tensor inversion applied to the 2004 mid-Niigata prefecture earthquake, Japan. Geophys J Int 167:1317-1331

Kagan YY (1991) 3-D rotation of double-couple earthquake sources. Geophys J Int 106:709-716

Kagan YY (2007) Simplified algorithms for calculating double-couple rotation. Geophys J Int 171:411-418

Kawakatsu H (1995) Automated near-realtime CMT inversion. Geophys Res Lett 22:2569-2572

Kennet BLN, Engdahl ER, Buland R (1995) Constraints on seismic velocities in the Earth from travel times. Geophys J Int 122:108-124

Kobayashi M, Takemura S, Yoshimoto K (2015) Frequency and distance changes in the apparent P-wave radiation pattern: effects of seismic wave scattering in the crust inferred from dense seismic observations 
and numerical simulations. Geophys J Int 202:1895-1907. doi:10.1093/ gji/ggv263

Kumagai H, Nakano N, Maeda T, Yepes H, Palacios P, Ruiz M et al (2010) Broadband seismic monitoring of active volcanoes using deterministic and stochastic approaches. J Geophys Res 115:B08303. doi:10.1029/200 9JB006889

Kumagai H, Saito T, O'Brien G, Yamashina T (2011) Characterization of scattered seismic wavefields simulated in heterogeneous media with topography. J Geophys Res 116:B03308. doi:10.1029/2009JB007718

Kumagai H, Pulido N, Fukuyama E, Aoi S (2012) Strong localized asperity of the 2011 Tohoku-Oki earthquake, Japan. Earth Planets Space 64:649-654. doi:10.5047/eps.2012.01.004

Liu H-L, Helmberger DV (1985) The 23:19 aftershock of the 15 October 1979 Imperial Valley earthquake: more evidence for an asperity. Bull Seismol Soc Am 75:689-708

Matsumoto T, Hori S, Matsubayashi H (2009) Broadband seismic observationNIED F-net. Zisin 61:S9-S18 (in Japanese with English abstract)

Melosantos AA, Soriano KVC, Alcones PCM, Pantig JU, Bonita JD, Narag IC et al (2015) Performance of broadband seismic network of the Philippines. J Disaster Res 10:8-17

Nakano M, Kumagai H, Inoue H (2008) Waveform inversion in the frequency domain for the simultaneous determination of earthquake source mechanism and moment function. Geophys J Int 173:1000-1011. doi:10.1111/j.1365-246X.2008.03783.x

Nakano M, Yamashina T, Kumagai H, Inoue H, Sunarjo (2010a) Centroid moment tensor catalogue of Indonesia. Phys Earth Planet Inter 183:456-467

Nakano M, Kumagai H, Toda S, Ando R, Yamashina T, Inoue H, Surajo (2010b) Source model of an earthquake doublet that occurred in a pull-apart basin along the Sumatran fault, Indonesia. Geophys J Int 181:141-153. doi:10.1111/j.1365-246X.2010.04511.x

Nakano M, Citak S, Kalafat D (2015) Focal mechanism determinations of earthquakes along the North Anatolian fault, beneath the Sea of Marmara and the Aegean Sea. Earth Planets Space 67:159. doi:10.1186/ s40623-015-0330-z
Okada Y, Kasahara K, Sadaki H, Obara K, Sekiguchi S, Fujiwara H, Yamamoto A (2004) Recent progress of seismic observation networks in Japan-HInet, F-net, K-NET and KiK-net. Earth Planets Space 56:25-28

Punongbayan J, Kumagai H, Pulido N, Bonita JD, Nakano M, Yamashina T et al (2015) Development and operation of a regional moment tensor analysis system in the Philippines: contributions to the understanding of recent damaging earthquakes. J Disaster Res 10:25-34

Ristau J (2008) Implementation of routine regional moment tensor analysis in New Zealand. Seismol Res Lett 79:400-415. doi:10.1785/gssrk.79.3.400

Ristau J (2013) Update of regional moment tensor analysis for earthquakes in New Zealand and adjacent offshore regions. Bull Seismol Soc Am 103:2520-2533. doi:10.1785/0120120339

Scognamiglio L, Tinti E, Michelini A (2009) Real-time determination of seismic moment tensor for the Italian region. Bull Seismol Soc Am 99:2223-2242. doi:10.1785/0120090104

Sipkin SA (1994) Rapid determination of global moment-tensor solutions. Geophys Res Lett 21:1667-1670

Takemura S, Furumura T, Saito T (2009) Distortion of the apparent S-wave radiation pattern in the high-frequency wavefield: TottriKen Seibu, Japan, earthquake of 2000. Geophys J Int 178:950-961. doi:10.1111/j.1365-246X.2009.04210.x

Takemura S, Furumura T, Maeda T (2015) Scattering of high-frequency seismic waves caused by irregular surface topography and small-scale velocity inhomogeneity. Geophys J Int 201:459-474. doi:10.1093/gji/ggv038

Tsuruoka H, Kawakatsu H, Urabe T (2009) GRiD MT (grid-based real-time determination of moment tensors) monitoring the long-period seismic wavefield. Phys Earth Planet Inter 175:8-16. doi:10.1016/j.pepi.2008.02.014

Zahradník J, Plešinger A (2005) Long-period pulses in broadband records of near earthquakes. Bull Seism Soc Am 95:1928-1939. doi:10.1785/0120040210

Zahradník J, Plešinger A (2010) Toward understanding subtle instrumentation effects associated with weak seismic events in the near field. Bull Seismol Soc Am 100:59-73. doi:10.1785/0120090087

\section{Submit your manuscript to a SpringerOpen ${ }^{\odot}$ journal and benefit from:}

- Convenient online submission

- Rigorous peer review

- Immediate publication on acceptance

- Open access: articles freely available online

- High visibility within the field

- Retaining the copyright to your article

Submit your next manuscript at $>$ springeropen.com 